Article

\title{
Impact of Increased End-Tidal Carbon Dioxide on Continuous Noninvasive Hemoglobin Monitoring during Laparoscopic Gastrectomy: A Randomized Controlled Study
}

\author{
Ha-Yeon Kim ${ }^{1}{ }^{\mathbb{D}}$, Jong-Bum Choi ${ }^{1}$, Sang-Uk Han ${ }^{2}$, Hye-Sun Lee ${ }^{3} \mathbb{D}$, Kyuhyeok Lee ${ }^{1}$ and Ji-Eun Kim ${ }^{1, *(D)}$ \\ 1 Department of Anesthesiology and Pain Medicine, Ajou University School of Medicine, Suwon 16499, Korea; \\ hayeon@aumc.ac.kr (H.-Y.K.); romeojb@aumc.ac.kr (J.-B.C.); mybfgg@gmail.com (K.L.) \\ 2 Department of Surgery, Ajou University School of Medicine, Suwon 16499, Korea; hansu@aumc.ac.kr \\ 3 Biostatistics Collaboration Unit, Yonsei University College of Medicine, Seoul 03722, Korea; HSLEE1@yuhs.ac \\ * Correspondence: beye98@aumc.ac.kr; Tel.: +82-31-219-5575
}

\section{check for} updates

Citation: Kim, H.-Y.; Choi, J.-B.; Han, S.-U.; Lee, H.-S.; Lee, K.; Kim, J.-E. Impact of Increased End-Tidal Carbon Dioxide on Continuous Noninvasive Hemoglobin Monitoring during Laparoscopic Gastrectomy: A Randomized Controlled Study. J. Pers. Med. 2022 12, 160. https://doi.org/10.3390/ jpm12020160

Academic Editor: Lorenza Rimassa

Received: 17 November 2021

Accepted: 10 January 2022

Published: 26 January 2022

Publisher's Note: MDPI stays neutral with regard to jurisdictional claims in published maps and institutional affiliations.

Copyright: () 2022 by the authors Licensee MDPI, Basel, Switzerland. This article is an open access article distributed under the terms and conditions of the Creative Commons Attribution (CC BY) license (https:// creativecommons.org/licenses/by/ $4.0 /)$.

\begin{abstract}
The pulse CO-Oximetry allows continuous, noninvasive monitoring of hemoglobin ( $\mathrm{SpHb}$ ). We assessed the impact of increased end-tidal carbon dioxide $\left(\mathrm{EtCO}_{2}\right)$ on the accuracy and trending ability of $\mathrm{SpHb}$ in laparoscopic surgery. Participants $(n=64)$ were randomly allocated to the low carbon dioxide $\left(\mathrm{CO}_{2}\right)$ group $\left(\mathrm{EtCO}_{2}: 30-35 \mathrm{mmHg}\right)$ or the high $\mathrm{CO}_{2}$ group $\left(\mathrm{EtCO}_{2}: 40-45 \mathrm{mmHg}\right)$. The $\mathrm{SpHb}$ and laboratory hemoglobin $(\mathrm{tHb})$ were obtained during surgery. The correlation coefficient $(\mathrm{r})$ between $\mathrm{SpHb}$ and $\mathrm{tHb}$ showed greater tendency in the low $\mathrm{CO}_{2}$ group $(\mathrm{r}=0.68)$ than in the high $\mathrm{CO}_{2}$ group $(\mathrm{r}=0.43)$. The bias (precision) was $-1.18(1.09)$ with a limit of agreement (LOA) of -3.31 to 0.95 in low $\mathrm{CO}_{2}$ group and -1.02 (1.24) with a LOA of -3.45 to 1.42 in high $\mathrm{CO}_{2}$ group; they did not differ significantly between the groups $(p=0.246)$. The low $\mathrm{CO}_{2}$ group showed a high concordance rate of $95.9 \%$ and a moderate correlation between $\Delta \mathrm{SpHb}$ and $\Delta \mathrm{tHb}(\mathrm{r}=0.53)$. However, the high $\mathrm{CO}_{2}$ group showed a concordance rate of $77.8 \%$ and no correlation between $\Delta \mathrm{SpHb}$ and $\Delta \mathrm{tHb}(\mathrm{r}=0.11)$. In conclusion, increased $\mathrm{EtCO}_{2}$ significantly reduced the trending ability of $\mathrm{SpHb}$ during laparoscopic surgery. Caution should be executed when interpreting $\mathrm{SpHb}$ values during laparoscopic surgery in patients with hypercapnia.
\end{abstract}

Keywords: hemoglobins; hypercapnia; laparoscopy; oximetry; transcutaneous blood gas monitoring

\section{Introduction}

To date, laparoscopic surgery has expanded to various surgeries because of its minimal invasiveness, few complications, and rapid recovery. Despite numerous benefits, pneumoperitoneum is required during laparoscopic surgery to secure the surgical view; however, it is associated with some disadvantages, such as excessive carbon dioxide $\left(\mathrm{CO}_{2}\right)$ retention and underestimated blood loss because of the limited view through the scope [1]. Moreover, pneumoperitoneum stimulates the sympathetic nervous system, leading to hemodynamic changes [2], which may be confused with changes of vital signs related to blood loss. Thus, rapid assessment of the hemoglobin $(\mathrm{Hb})$ concentration is essential even in laparoscopy.

The Radical-7 pulse CO-Oximetry is a device that allows monitoring of continuous, noninvasive hemoglobin $(\mathrm{SpHb})$. It was developed in the process of overcoming pulse oximetry's shortcomings and uses 8-wavelength spectrometry, whereas pulse oximetry uses 2-wavelength spectrometry [3]. Compared to a laboratory $\mathrm{Hb}(\mathrm{tHb}), \mathrm{SpHb}$ enables real-time monitoring of $\mathrm{Hb}$ changes without invasiveness, time-delay, unnecessary labor, and collection of serial blood samples. Considering that one-third of transfusions in the operation room are administered without first obtaining $\mathrm{tHb}$ value [4], $\mathrm{SpHb}$ can help to minimize unnecessary blood sampling and transfusions along with reducing the associated costs and improving the quality of care, which is a major public health issue $[5,6]$. 
Several clinical studies have investigated the accuracy, precision, and trending ability of $\mathrm{SpHb}$ in various conditions including indigo carmine, anemia, cardiopulmonary bypass, transplantation, trauma, dark-skinned and hemodilution [7-12]. In a previous study, altered arterial $\mathrm{CO}_{2}$ pressure $\left(\mathrm{PaCO}_{2}\right)$ impaired the agreement between oxygen saturation calculated from arterial blood analyzers and that measured with pulse oximetry [13]. Pulse oximetry and pulse CO-Oximetry have technological similarity based on light absorption through a finger sensor. Recently, an observational pilot study suggested that the values of $\mathrm{SpHb}$ may be affected by the presence of $\mathrm{CO}_{2}$ insufflation [14]. Therefore, we hypothesized that increased end-tidal $\mathrm{CO}_{2}\left(\mathrm{EtCO}_{2}\right)$ would affect sensing of $\mathrm{SpHb}$ and reduce the accuracy and trending ability of $\mathrm{SpHb}$ during laparoscopic surgery. This study aimed to assess the impact of increased $\mathrm{EtCO}_{2}$ on the accuracy and trending ability of $\mathrm{SpHb}$ in patients undergoing laparoscopic gastrectomy.

\section{Materials and Methods}

\subsection{Study Design and Patients}

This randomized, double-blinded, controlled study was conducted at Ajou University Health System. The present study was approved by the Ajou Hospital Institutional Review Board (AJIRB-MED-OBS-17-339, 8 January 2018) and registered prior to patient enrollment at ClinicalTrial.gov (NCT03430778, principal investigator: JEK, registration date: 13 February 2018). Written informed consent was obtained from all participants. This manuscript adheres to the applicable CONSORT guidelines.

Patients undergoing elective laparoscopic gastrectomy with an American Society of Anesthesiologists physical status I-III, aged 19-85 years, were included. Exclusion criteria were prior surgery involving the hand, infection, hematologic diseases, or refusal to participate in this study.

\subsection{Interventions}

Participants were randomly allocated to one of the two groups by computer-generated randomization (http:/ / www.random.org, 14 February 2018): the low $\mathrm{CO}_{2}$ group or the high $\mathrm{CO}_{2}$ group. The low $\mathrm{CO}_{2}$ group participants were maintained at an $\mathrm{EtCO}_{2}$ level of 30-35 mmHg by adjusting the tidal volume and inspiratory rate within a peak inspiratory pressure $\leq 29 \mathrm{cmH}_{2} \mathrm{O}$ during surgery. The high $\mathrm{CO}_{2}$ group participants were maintained at an $\mathrm{EtCO}_{2}$ level of $40-45 \mathrm{mmHg}$ during surgery. Group assignment information was concealed in a sealed, opaque envelope. Before anesthesia induction, the envelope was opened by an independent investigator who performed all interventions but was not involved in outcome assessment (J.B.C.). He adjusted the respiratory rate according to the group assignment in all patients. The outcome assessor who did not perceive the concept of study conducted the blood sampling and data recording (K.L.). The other investigators who did not know the patient's group assignment collected the data of the blood analyzer from electrical medical records (H.Y.K. and J.E.K).

On patients' arrival to the operating room, basic monitoring (pulse oximetry, electrocardiography, and non-invasive blood pressure measurement) was performed. A spectrophotometric adhesive SpHb sensor (Rainbow R1 25, Rev E; Masimo, Irvine, CA, USA) was applied to the patients' fourth finger and was covered with an impermeable black shield. $\mathrm{SpHb}$ levels were continuously monitored with a Radical-7 Pulse CO-Oximetry (Masimo, Irvine, CA, USA; software version 1451). Anesthesia was induced with intravenous (IV) propofol ( $2 \mathrm{mg} / \mathrm{kg}$ ) and remifentanil (3.0-4.0 $\mathrm{ng} / \mathrm{mL})$ using a target-controlled infusion, followed by rocuronium $(1 \mathrm{mg} / \mathrm{kg})$. After endotracheal intubation, mechanical ventilation was initiated with a tidal volume of $8 \mathrm{~mL} / \mathrm{kg}$ and an inspired oxygen fraction $\left(\mathrm{FiO}_{2}\right)$ of 0.5. Anesthesia was maintained with a remifentanil (target concentration, $0.5-4.0 \mathrm{ng} / \mathrm{mL}$ ), sevoflurane (2-2.5\%), and rocuronium infusion within a surgical pleth index of 30-50, bispectral index score of 40-60, and train-of-four of 1-2. Lactate Ringer's solution was infused at a rate of $5-10 \mathrm{~mL} / \mathrm{kg} / \mathrm{h}$. A radial arterial catheter was placed on the contralateral side of patients as the $\mathrm{SpHb}$ sensor. The arterial blood was sampled to measure $\mathrm{tHb}$ 
using the satellite CO-Oximetry (Stat Profile pHOx Ultra; Nova Biomedical, Waltham, MA, USA). In case of the mean arterial pressure (MAP) $<60 \mathrm{mmHg}$, an IV bolus of ephedrine $(4 \mathrm{mg})$ was primarily administered, and infusion of norepinephrine was administered as needed. At the end of the surgery, an IV of propacetamol $(1 \mathrm{~g})$ and ramosetron $(0.3 \mathrm{mg})$ was administered for postoperative analgesia and antiemetic treatment. After confirming the train-of-four $\geq 2$ using a nerve stimulator, an IV of sugammadex $(2 \mathrm{mg} / \mathrm{kg})$ was administered for reversal of the neuromuscular block. After confirming an adequate tidal volume, patients were extubated and transferred to a post-anesthesia care unit.

\subsection{Data Collection}

Arterial blood sampling was obtained after confirming that $\mathrm{SpHb}$ was unchanged for $30 \mathrm{~s}$. Simultaneous $\mathrm{SpHb}$ and the perfusion index (PI) were recorded within $10 \mathrm{~s}$ after arterial blood sampling. In vivo adjustment (calibration) was not conducted. Hemodynamics (heart rate $[\mathrm{HR}]$ and MAP), data on the monitor $\left(\mathrm{SpHb}, \mathrm{PI}\right.$, and $\left.\mathrm{EtCO}_{2}\right)$, and data from the blood analyzer $\left(\mathrm{pH}, \mathrm{PaCO}_{2}\right.$, arterial oxygen pressure $\left[\mathrm{PaO}_{2}\right], \mathrm{tHb}$, and bicarbonate) were collected at five time points: after anesthesia induction; at 30, 60, and $90 \mathrm{~min}$ after pneumoperitoneum; and at the end of the surgery. Intraoperative vasopressor use was also recorded.

\subsection{Statistical Analysis}

The primary end point was the bias $(=\mathrm{SpHb}-\mathrm{tHb})$. The sample size was calculated based on the bias. In a previous study, the standard deviation (SD) of bias during use of pulse CO-Oximetry was $0.92 \mathrm{~g} / \mathrm{dL}$ [15]. Considering that a mean difference of 0.8 in bias was significant, 28 participants were required in each group for a significance level of $5 \%$ and a power of $90 \%$. Considering the dropout rate of $25 \%, 70$ patients were included.

All paired data $(\mathrm{SpHb}-\mathrm{tHb})$ and changes in $\mathrm{SpHb}(\Delta \mathrm{SpHb})$ and $\mathrm{tHb}(\Delta \mathrm{tHb})$ between two consecutive measurements were analyzed. $\mathrm{SpHb}$ values were excluded in the analysis when the PI was $<1$, because a low PI affects the accuracy.

Correlation between simultaneous $\mathrm{SpHb}$ and $\mathrm{tHb}$ measurement pairs was depicted in a scatter plot, and coefficients of determination ( $\mathrm{r}$ values) were calculated by Pearson correlation analysis. For the accuracy of $\mathrm{SpHb}$, a modified Bland-Altman's method was used with consideration of multiple measurements per individual. The precision was defined as 1 SD of the bias. The $95 \%$ limits of agreement (LOA) were presented by calculating the interval defined by the bias $\pm 1.96 \mathrm{SD}$. The correlation coefficient between $\mathrm{SpHb}$ and $\mathrm{tHb}$ with repeated observations for each patient was estimated by using a mixed-effects model. For trend analysis, the four-quadrant plot was used with differences of $\Delta \mathrm{SpHb}$ and $\Delta \mathrm{tHb}$. A central exclusion zone of $1 \mathrm{~g} / \mathrm{dL}$ was applied to compensate for intrinsic $\mathrm{SpHb}$ bias. The effect of $\mathrm{PaCO}_{2}$ on the bias and SD was analyzed using the $\mathrm{F}$ test and $t$ test. The relationship between bias and $\mathrm{PaCO}_{2}$ was analyzed with a mixed-effects model for different $\mathrm{PaCO}_{2}$ ranges $\left(\mathrm{PaCO}_{2}<35 \mathrm{mmHg}, 35 \mathrm{mmHg} \leq \mathrm{PaCO}_{2}<40 \mathrm{mmHg}\right.$, and $\mathrm{PaCO}_{2} \geq 40 \mathrm{mmHg}$ ).

Data are presented as mean \pm SD [range], median [range], or number of patients (\%). Normality of distribution was assessed with the Shapiro-Wilk test. Parametric and nonparametric data were analyzed using the Student's t-test and Mann-Whitney test. Categorical data were compared using the chi-square test or Fisher's exact test. Repeated measured data were analyzed using the linear mixed model and post-hoc analysis. When the interaction was statistically significant, the $p$-value was adjusted with Bonferroni correction. A $p$ value $<0.05$ was considered statistically significant. Statistical analysis was conducted with SPSS for Windows (version 25.0; IBM Corp., Armonk, NY, USA) and SAS (version 9.4; SAS Inc., Cary, NC, USA). 


\section{Results}

\subsection{Study Population and Intraoperative Characteristics}

Seventy patients were enrolled and randomized between January 2019 and May 2019, but six patients withdrawn because of conversion to open surgery $(n=5)$ and closure due to abdominal seeding $(n=1)$ (Figure 1$)$.

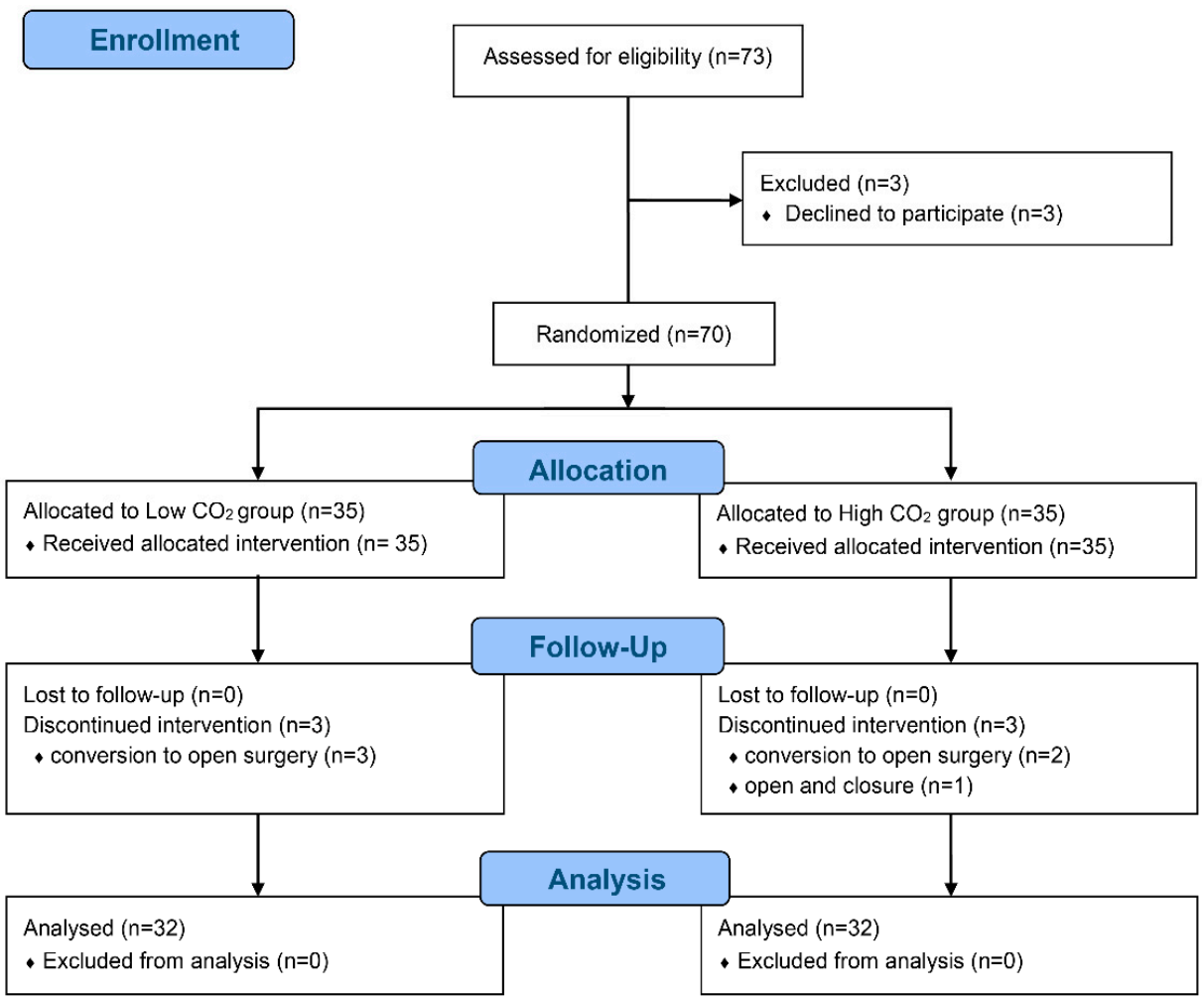

Figure 1. CONSORT flow diagram.

There were no significant differences in patient characteristics and surgical data between the high and low $\mathrm{CO}_{2}$ groups (Table 1 ). No patient received a transfusion during surgery. Both HR and MAP were adequately maintained and comparable between the groups $\left(\mathrm{P}_{\text {group } \times \text { time }}=0.787\right.$ and $\mathrm{P}_{\text {group } \times \text { time }}=0.423$, respectively $)$. The $\mathrm{PaO}_{2}$ and $\mathrm{pH}$ were also comparable between the groups $\left(P_{\text {group } \times \text { time }}=0.423\right.$ and $\left.P_{\text {group } \times \text { time }}=0.138\right)$; however, $\mathrm{PaCO}_{2}$ and bicarbonate were significantly higher in the high $\mathrm{CO}_{2}$ group than in the low $\mathrm{CO}_{2}$ group at all time points $\left(\mathrm{P}_{\text {group } \times \text { time }}<0.001\right.$ and $\mathrm{P}_{\text {group } \times \text { time }}=0.020$, respectively $)$.

Table 1. Patient characteristics and perioperative profiles.

\begin{tabular}{lccc}
\hline & $\begin{array}{c}\text { Low } \mathrm{CO}_{2} \text { Group } \\
(\boldsymbol{n}=\mathbf{3 2})\end{array}$ & $\begin{array}{c}\text { High CO } \\
(\boldsymbol{n}=\mathbf{3 2})\end{array}$ & $p$-Value \\
\hline Age $(\mathrm{yr})$ & $62 \pm 14$ & $61 \pm 12$ & 0.871 \\
Height $(\mathrm{cm})$ & $165.6 \pm 8.8$ & $166.1 \pm 7.4$ & 0.808 \\
Weight $(\mathrm{kg})$ & $67.6 \pm 12.3$ & $66.8 \pm 10.6$ & 0.800 \\
Sex (male/female) & $27 / 5$ & $27 / 5$ & $>0.999$ \\
ASA physical status $(1 / 2 / 3)$ & $15 / 14 / 3$ & $15 / 14 / 3$ & $>0.999$ \\
Diabetes & $4(13 \%)$ & $8(25 \%)$ & 0.200 \\
COPD & 0 & $2(6 \%)$ & 0.492 \\
Crystalloid + colloid (mL) & $1575(1453-1775)$ & $1600(1200-2075)$ & 0.962 \\
Urine (mL) & $165(110-308)$ & $138(95-290)$ & 0.629 \\
Bleeding (mL) & $100(100-150)$ & $100(100-150)$ & 0.482 \\
Infusion of norepinephrine & $4(13 \%)$ & $6(19 \%)$ & 0.491 \\
Infusion of isosorbide dinitrate & $2(6 \%)$ & $2(6 \%)$ & $>0.999$ \\
Perfusion index (\%) & $3.9 \pm 2.0$ & $4.2 \pm 2.5$ & 0.145 \\
SpHb (g/dL) & $10.6 \pm 1.2$ & $11.2 \pm 1.2$ & $<0.001$ \\
\hline
\end{tabular}


Table 1. Cont.

\begin{tabular}{lccc}
\hline & $\begin{array}{c}\text { Low } \begin{array}{c}\mathrm{CO}_{2} \text { Group } \\
(\boldsymbol{n}=\mathbf{3 2})\end{array} \\
\mathrm{tHb}(\mathrm{g} / \mathrm{dL})\end{array}$ & $\begin{array}{c}\text { High } \mathbf{C O}_{\mathbf{2}} \text { Group } \\
(\boldsymbol{n}=\mathbf{3 2})\end{array}$ & $p$-Value \\
$\mathrm{EtCO}_{2}(\mathrm{mmHg})$ & $11.7 \pm 1.4$ & $12.2 \pm 1.1$ & 0.003 \\
$\mathrm{PaCO}_{2}(\mathrm{mmHg})$ & $31.8 \pm 2.3$ & $42.0 \pm 2.9$ & $<0.001$ \\
Pneumoperitoneum time (min) & $32.0 \pm 3.2$ & $42.3 \pm 4.6$ & $<0.001$ \\
Anesthesia time (min) & $131(116-145)$ & $119(98-156)$ & 0.383 \\
PACU profiles & $198 \pm 37$ & $188 \pm 46$ & 0.351 \\
$\quad$ & & \\
Pain score & $7(6-8)$ & $7(6.5-9)$ & \\
Nausea $(1 / 2 / 3 / 4)$ & $2 / 26 / 3 / 0$ & $1 / 30 / 1 / 0$ & \\
$\quad$ Antiemiting & 0 & $1(3 \%)$ & \\
Analgesics & $3(10 \%)$ & $30(94 \%)$ & \\
Duration of PACU stay (min) & $29(94 \%)$ & $50(40-55)$ & \\
\hline
\end{tabular}

Values are presented as mean \pm standard deviation, median (interquartile range) or number of patients (\%). ASA American Society of Anesthesiologists; COPD, chronic obstructive pulmonary disease; $\mathrm{SpHb}$, the noninvasive hemoglobin by pulse $\mathrm{CO}$-oximeter; $\mathrm{tHb}$, laboratory hemoglobin; $\mathrm{EtCO}_{2}$, end-tidal carbon dioxide; $\mathrm{PaCO}_{2}$, arterial carbon dioxide pressure; PACU, post-anesthesia care unit.

\subsection{Collection of $\mathrm{SpHb}$ and $\mathrm{tHb}$ Values}

In total, 320 paired measurements of $\mathrm{SpHb}$ and $\mathrm{tHb}$ were collected from 64 patients. Twenty-five $\mathrm{SpHb}$ measurements $\left(7.8 \%, 13\right.$ in the low $\mathrm{CO}_{2}$ group and 12 in the high $\mathrm{CO}_{2}$ group) were excluded because the PI was $<1.0$. The mean PI values for the remaining $\mathrm{SpHb}$ measurements were $3.9 \pm 2.0[1-8.2] \%$ in the low $\mathrm{CO}_{2}$ group and $4.2 \pm 2.5[1-12] \%$ in the high $\mathrm{CO}_{2}$ group (Table 1). Finally, 295 paired measurements of $\mathrm{SpHb}$ and $\mathrm{tHb}$ were analyzed (92.2\%, 147 in the low $\mathrm{CO}_{2}$ group and 148 in the high $\mathrm{CO}_{2}$ group). The $\mathrm{SpHb}$ and $\mathrm{tHb}$ values were significantly lower in the low $\mathrm{CO}_{2}$ group than in the high $\mathrm{CO}_{2}$ group $(p<0.001$ and $p=0.003$, respectively, Table 1$)$.

\subsection{Accuracy and Trending Ability of $\mathrm{SpHb}$}

In a scatter plot with all $\mathrm{SpHb}$ and $\mathrm{tHb}$ data points, there was a strong positive correlation between $\mathrm{SpHb}$ and $\mathrm{tHb}$ in the low $\mathrm{CO}_{2}$ group but a moderate positive correlation in the high $\mathrm{CO}_{2}$ group (Figure 2): the $\mathrm{r}$ values were 0.68 (95\% confidence interval [CI] 0.58 to 0.76 ) and 0.43 ( $95 \% \mathrm{CI} 0.29$ to 0.55 ) for the low and high $\mathrm{CO}_{2}$ groups, respectively $(p=0.153)$. Results of the modified Bland-Altman's analysis for repeated measurements are shown in Figure 3. The bias (precision) values were -1.18 (1.09) with an LOA of -3.31 to 0.95 in the low $\mathrm{CO}_{2}$ group and -1.02 (1.24) with an LOA of -3.45 to 1.42 in the high $\mathrm{CO}_{2}$ group, and they did not differ significantly between the groups $(p=0.246)$.

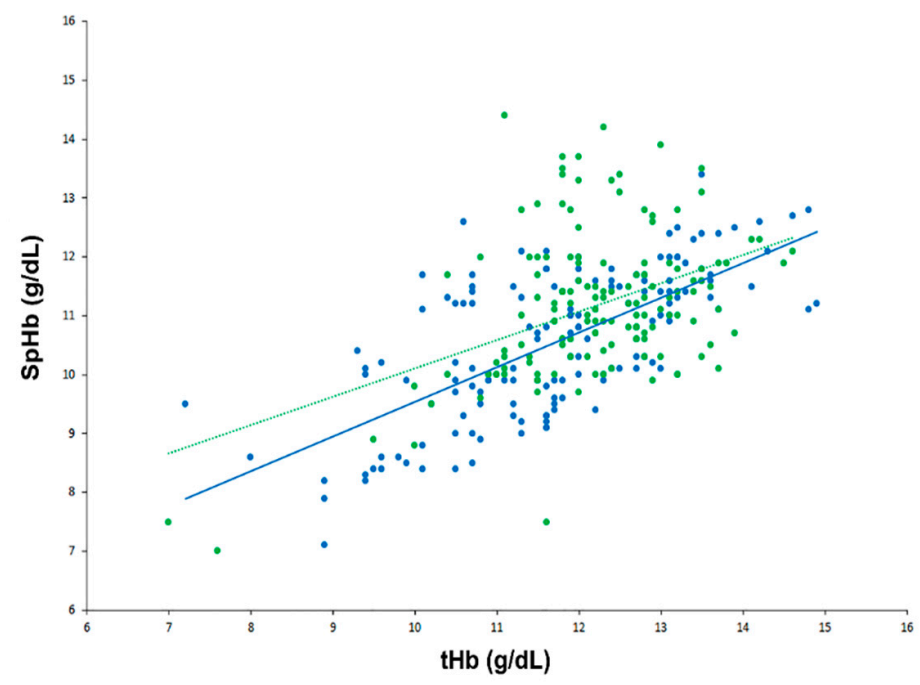

Figure 2. Scatter plot showing real-time continuous hemoglobin and laboratory hemoglobin data in the low carbon dioxide $\left(\mathrm{CO}_{2}\right)$ (blue) and high $\mathrm{CO}_{2}$ groups (green). 
(a)

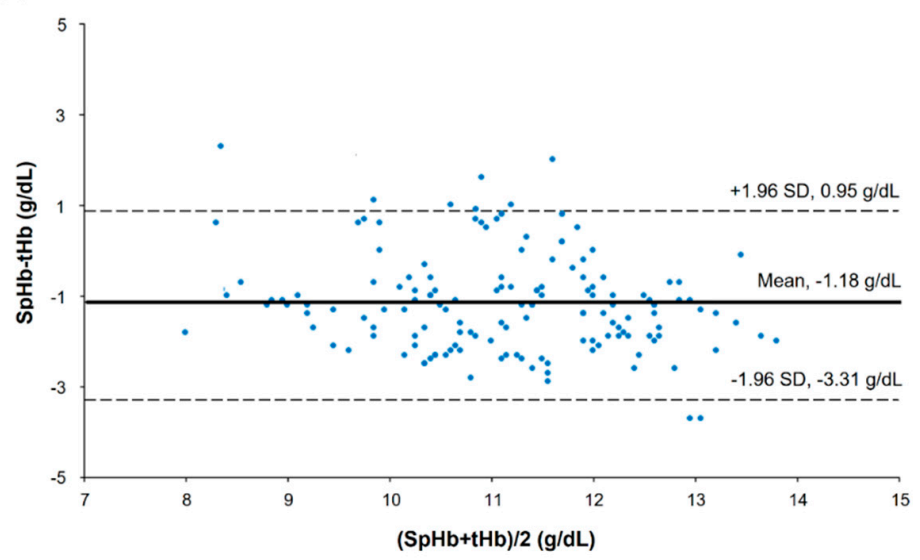

(b)

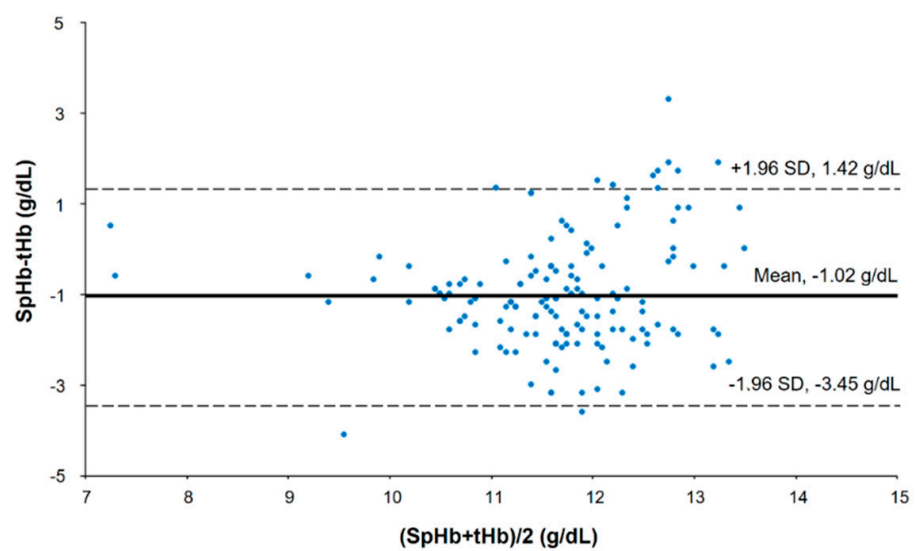

Figure 3. Bland-Altman's plot showing repeated measurements in the low carbon dioxide $\left(\mathrm{CO}_{2}\right)(\mathbf{a})$ and high $\mathrm{CO}_{2}$ groups (b).

The four-quadrant plot of $\Delta \mathrm{SpHb}$ and $\Delta \mathrm{tHb}$ is shown in Figure 4 . The low $\mathrm{CO}_{2}$ group showed a highly acceptable concordance rate of $95.9 \%$ (47 of 49 ) and a moderate positive correlation between $\Delta \mathrm{SpHb}$ and $\Delta \mathrm{tHb}$ (Figure $4 \mathrm{a}$ ): the r value was 0.53 (95\% CI 0.38 to 0.65 ). However, the high $\mathrm{CO}_{2}$ group showed a lower acceptable concordance rate of $77.8 \%$ (28 of 36) than the low $\mathrm{CO}_{2}$ group and no correlation between $\Delta \mathrm{SpHb}$ and $\Delta \mathrm{tHb}$ (Figure $4 \mathrm{~b}$ ): the r value was $0.11(95 \% \mathrm{CI}-0.08$ to 0.29$)$.

(a)

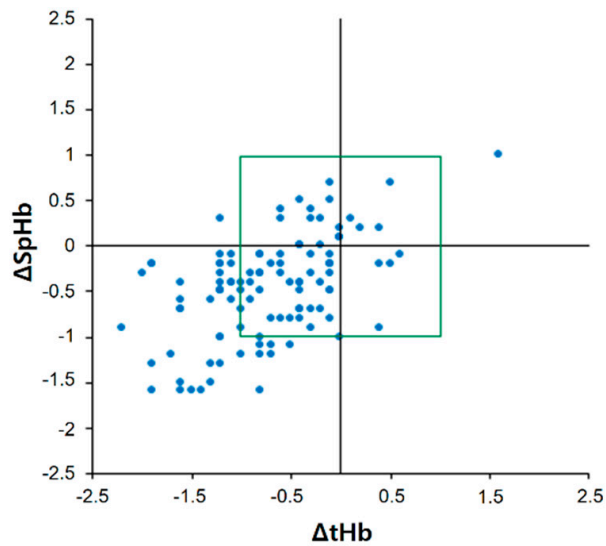

(b)

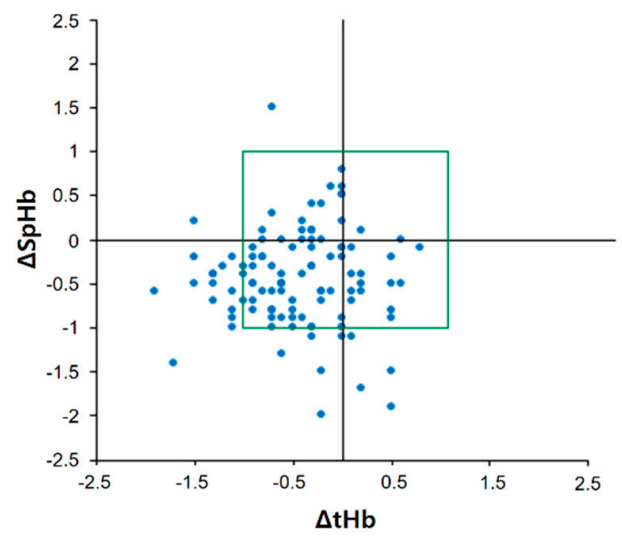

Figure 4. Four-quadrant plot showing changes in real-time continuous hemoglobin values and laboratory hemoglobin values in the low carbon dioxide $\left(\mathrm{CO}_{2}\right)(\mathbf{a})$ and high $\mathrm{CO}_{2}$ groups $(\mathbf{b})$. 


\subsection{Comparisons According to the $\mathrm{PaCO}_{2}$ Ranges}

According to the $\mathrm{PaCO}_{2}$ ranges, bias was significantly increased in the $\mathrm{PaCO}_{2} \geq 45 \mathrm{mmHg}$ range compared with those in the $\mathrm{PaCO}_{2}<35 \mathrm{mmHg}$ and $35 \leq \mathrm{PaCO}_{2}<45 \mathrm{mmHg}$ ranges $(p=0.020$ and $p=0.004$, respectively; Table 2$)$.

Table 2. Accuracy of $\mathrm{SpHb}$ by $\mathrm{PaCO}_{2}$ range.

\begin{tabular}{lcc}
\hline & Bias (95\% CI) (g/dL) & SD (g/dL) \\
\hline $\mathrm{PaCO}_{2}<35 \mathrm{mmHg}_{35 \leq \mathrm{PaCO}_{2}<45 \mathrm{mmHg}^{*}}$ & $-1.09(-1.28$ to -0.90$)$ & 1.06 \\
$45 \mathrm{mmHg} \leq \mathrm{PaCO}_{2}$ & $-0.97(-1.17$ to -0.76$)$ & 1.22 \\
\hline
\end{tabular}

Bias $=$ the $\mathrm{SpHb}$-laboratory hemoglobin. ${ }^{*} p=0.020$ compared with $\mathrm{PaCO}_{2}<35 \mathrm{mmHg}, p=0.004$ compared with $35 \leq \mathrm{PaCO}_{2}<45 \mathrm{mmHg}$. $\mathrm{SpHb}$, the noninvasive hemoglobin by pulse $\mathrm{CO}$-oximeter; $\mathrm{CI}$, confidence intervals, $\mathrm{SD}$, standard deviation; $\mathrm{PaCO}_{2}$, arterial carbon dioxide pressure.

\section{Discussion}

To our knowledge, this randomized controlled study is the first to assess the impact of increased $\mathrm{EtCO}_{2}$ on $\mathrm{SpHb}$ during laparoscopic surgery. The bias did not differ between the groups. However, the correlation between $\mathrm{SpHb}$ and $\mathrm{tHb}$ was strong in the low $\mathrm{CO}_{2}$ group but moderate in the high $\mathrm{CO}_{2}$ group. In addition, the concordance rate between $\mathrm{SpHb}$ and $\mathrm{tHb}$ was more acceptable in the low $\mathrm{CO}_{2}$ group than in the high $\mathrm{CO}_{2}$ group. Moreover, the correlation between $\Delta \mathrm{SpHb}$ and $\Delta \mathrm{tHb}$ was moderate in the low $\mathrm{CO}_{2}$ group but negligible in the high $\mathrm{CO}_{2}$ group. Lastly, the bias was significantly increased in the range of $\mathrm{PaCO}_{2} \geq 45 \mathrm{mmHg}$.

Pulse oximetry and pulse CO-Oximetry are based on the measurement of the differential optical density of light that pass through the tissue. The accuracy of pulse oximetry, when being evaluated by the difference between the oxygen saturation by pulse oximetry and that in the arterial blood, was affected by several factors [16,17]. Similarly, the accuracy of pulse CO-Oximetry has been evaluated using the $\mathrm{SpHb}$ and $\mathrm{tHb}$ values. In there, $\mathrm{SpHb}$ has shown clinical usefulness but was affected by various factors [7-12]. In previous studies, altered $\mathrm{PaCO}_{2}$ levels affected the accuracy and reliability of oxygen saturation in pulse oximetry [13]. Hence, we differentiated the $\mathrm{EtCO}_{2}$ levels between the groups and assessed the $\mathrm{SpHb}$ values.

In our study, increased $\mathrm{EtCO}_{2}$ did not affect the accuracy of $\mathrm{SpHb}$ in terms of the similar bias between the groups, although the low $\mathrm{CO}_{2}$ group showed a lower precision and a narrower LOA than the high $\mathrm{CO}_{2}$ group. The bias values in the low and high $\mathrm{CO}_{2}$ groups seem to be adequate in terms of accuracy, by being within $\leq 1.5 \mathrm{~g} / \mathrm{dL}$ of the $\mathrm{tHb}$ as proposed by Miller et al. [18], but they were slightly high compared to a meta-analysis result of $-0.27 \mathrm{~g} / \mathrm{dL}$ performed in the operating room [19]. This may be because we did not conduct the calibration (in-vivo adjustment). If $\mathrm{SpHb}$ was calibrated with the initial $\mathrm{tHb}$, the bias in our study would be deceased, because a previous study reported that after calibration, bias and the SD of $\mathrm{SpHb}$ were reduced by $0.5 \mathrm{~g} / \mathrm{dL}$ compared to $\mathrm{tHb}$ in surgical patients [20].

In contrast to accuracy, increased $\mathrm{EtCO}_{2}$ reduced the trending ability of $\mathrm{SpHb}$ in our study, in which the levels of concordance and correlation between $\mathrm{SpHb}$ and $\mathrm{tHb}$ were strong enough to reduce the number of invasive blood samplings by pulse CO-Oximetry in the low $\mathrm{CO}_{2}$ group but less in the high $\mathrm{CO}_{2}$ group. Since inception of pulse CO-Oximetry in 2008, numerous studies investigating its ability have focused on the accuracy of $\mathrm{SpHb}$ as the absolute difference of $\mathrm{Hb}$ compared to conventional methods [21,22]. These studies showed reasonable accuracy for $\mathrm{SpHb}$, but certain patient conditions limited this. For example, Riess et al. investigated the use of $\mathrm{SpHb}$ during cardiac surgery and found $\mathrm{SpHb}$ to be accurate before but not after cardiopulmonary bypass. They concluded that sole reliance on $\mathrm{SpHb}$ for deciding transfusion is inappropriate [8]. A few $\mathrm{SpHb}$ studies have evaluated the trending ability and accuracy of $\mathrm{SpHb}[9,10,12]$. Barker et al. suggested that the primary value of $\mathrm{SpHb}$ is derived from a continuous, real-time measurement and 
trending rather than accuracy, and that $\mathrm{SpHb}$ is not an alternative to $\mathrm{tHb}$ but an additional trend monitor [23]. Downward, stable, or upward $\mathrm{SpHb}$ trends enable clinicians to quickly decide whether to transfuse a patient. Thus, altered trending ability of $\mathrm{SpHb}$ leads to time-delayed or unnecessary red blood cell transfusion. In our study, it may be clinically more meaningful that increased $\mathrm{EtCO}_{2}$ during laparoscopic surgery reduced the ability of trending in $\mathrm{SpHb}$ rather than not affecting the accuracy of $\mathrm{SpHb}$.

Several possibilities may explain the reduced ability of trending in $\mathrm{SpHb}$ in our study. First, pulse $\mathrm{CO}-\mathrm{Oximetry}$ measures the concentrations of four $\mathrm{Hb}$ types: oxyhemoglobin, deoxyhemoglobin, methemoglobin, and carboxyhemoglobin. Thus, increased $\mathrm{PaCO}_{2}$ may alter the wavelength reading because of increases in the amount of carbaminohemoglobin, considering that about $10 \%$ of the $\mathrm{CO}_{2}$ is carried as carbaminohemoglobin [24]. Second, $\mathrm{PaCO}_{2}$-related vasodilation causes dynamic circulation (opening) in an arteriovenous shunt at the fingertip $[25,26]$, which may lead to venous pulsation and spurious detection by pulse CO-Oximetry of venous blood as arterial. It is notable because deoxyhemoglobin can carry more $\mathrm{CO}_{2}$ than the oxygenated form (the Haldane effect) [24]. Third, increased $\mathrm{PaCO}_{2}$ causes a reduction in $\mathrm{CO}_{2}$-medicated extracellular $\mathrm{pH}$ [25], which can induce changes in red blood cell morphology [27].

There are several limitations to our study. First, $\mathrm{tHb}$ was measured using satellite $\mathrm{CO}-\mathrm{Oximetry}$, which has been the common method to measure $\mathrm{tHb}$ in the operating room. However, the International Committee for Standardization in Hematology recommends a central laboratory hematology analyzer that uses the cyanide method for $\mathrm{tHb}$ measurement [28]. Second, the study groups were divided according to $\mathrm{EtCO}_{2}$, and not $\mathrm{PaCO}_{2}$. Although $\mathrm{EtCO}_{2}$ measurement is a good non-invasive method to estimate $\mathrm{PaCO}_{2}, \mathrm{EtCO}_{2}$ may not predict the actual $\mathrm{PaCO}_{2}$ in certain circumstances. Third, we used an older version of $\mathrm{SpHb}$ sensors (Rev E), but updated $\mathrm{SpHb}$ sensors may show the different results. Fourth, all patients were transferred to the operating room for a scheduled surgery with stable hemodynamics and a $\mathrm{Hb}$ level within the normal range. Further studies are needed considering special conditions, such as low $\mathrm{Hb}$ levels or critical illness. Fifth, all adhesive $\mathrm{SpHb}$ sensors were applied to the fourth finger of each patient's left hand. Since differences in oxygen saturation among fingers or between dominant and non-dominant hands have been reported, this may have affected our results, although arterial catheterization was performed in the right arm and $\mathrm{SpHb}$ values with a PI $<1.0$ were excluded [29]. Sixth, we did not calibrate the $\mathrm{SpHb}$ with initial $\mathrm{tHb}$. However, for the assessment of $\Delta \mathrm{SpHb}$ and $\Delta \mathrm{tHb}$, calibration could have been beneficial to assess a drift over the increased $\mathrm{EtCO}_{2}$ or the time.

\section{Conclusions}

An increased $\mathrm{EtCO}_{2}$ significantly reduced the trending ability of $\mathrm{SpHb}$ in patients undergoing laparoscopic gastrectomy. Caution should be executed during decision-making regarding transfusion based on the $\mathrm{SpHb}$ value in patients with hypercapnia.

Author Contributions: Conceptualization, H.-Y.K. and J.-E.K.; methodology, K.L.; validation, J.-B.C. and S.-U.H.; formal analysis, H.-S.L.; investigation, H.-Y.K., K.L. and J.-E.K.; resources, J.-E.K.; data curation, H.-Y.K.; writing-original draft preparation, H.-Y.K.; writing—review and editing, J.-E.K.; visualization, H.-S.L.; supervision, H.-Y.K. and J.-E.K. All authors have read and agreed to the published version of the manuscript.

Funding: Financial support was provided by the National Institutes of Health of Korea (NRF) grant funded by the Korea government (MSIT) (No. 2017R1C1B5074930).

Institutional Review Board Statement: The study was conducted according to the guidelines of the Declaration of Helsinki, and approved by the Institutional Review Board of Ajou University Hospital (No. AJIRB-MED-OBS-17-339).

Informed Consent Statement: Written informed consent was obtained from all patients involved in the study. 
Data Availability Statement: The datasets used and analyzed during the current study are available from the corresponding author upon reasonable request.

Conflicts of Interest: The authors declare no conflict of interest.

\section{References}

1. Tomimaru, Y.; Noguchi, K.; Morita, S.; Imamura, H.; Iwazawa, T.; Dono, K. Is intraoperative blood loss underestimated in patients undergoing laparoscopic hepatectomy? World J. Surg. 2018, 42, 3685-3691. [CrossRef] [PubMed]

2. Atkinson, T.M.; Giraud, G.D.; Togioka, B.M.; Jones, D.B.; Cigarroa, J.E. Cardiovascular and ventilatory consequences of laparoscopic surgery. Circulation 2017, 135, 700-710. [CrossRef] [PubMed]

3. Shamir, M.Y.; Avramovich, A.; Smaka, T. The current status of continuous noninvasive measurement of total, carboxy, and methemoglobin concentration. Anesth. Analg. 2012, 114, 972-978. [CrossRef] [PubMed]

4. Frank, S.M.; Savage, W.J.; Rothschild, J.A.; Rivers, R.J.; Ness, P.M.; Paul, S.L.; Ulatowski, J.A. Variability in blood and blood component utilization as assessed by an anesthesia information management system. Anesthesiology 2012, 117, 99-106. [CrossRef]

5. Ribed-Sanchez, B.; Gonzalez-Gaya, C.; Varea-Diaz, S.; Corbacho-Fabregat, C.; Perez-Oteyza, J.; Belda-Iniesta, C. Economic analysis of the reduction of blood transfusions during surgical procedures while continuous hemoglobin monitoring is used. Sensors 2018, 18, 1367. [CrossRef]

6. Goodnough, L.T.; Shander, A. Patient blood management. Anesthesiology 2012, 116, 1367-1376. [CrossRef]

7. Isosu, T.; Satoh, T.; Oishi, R.; Imaizumi, T.; Hakozaki, T.; Obara, S.; Ikegami, Y.; Kurosawa, S.; Murakawa, M. Effects of indigo carmine intravenous injection on noninvasive and continuous total hemoglobin measurement. J. Clin. Monit. Comput. 2016, 30, 313-316. [CrossRef]

8. Riess, M.L.; Pagel, P.S. Noninvasively measured hemoglobin concentration reflects arterial hemoglobin concentration before but not after cardiopulmonary bypass in patients undergoing coronary artery or valve surgery. J. Cardiothorac. Vasc. Anesth. 2016, 30, 1167-1171. [CrossRef]

9. Erdogan Kayhan, G.; Colak, Y.Z.; Sanli, M.; Ucar, M.; Toprak, H.I. Accuracy of non-invasive hemoglobin monitoring by pulse CO-oximeter during liver transplantation. Minerva Anestesiol. 2017, 83, 485-492. [CrossRef]

10. Yang, S.; Hu, P.F.; Anazodo, A.; Gao, C.; Chen, H.; Wade, C.; Hartsky, L.; Miller, C.; Imle, C.; Fang, R.; et al. Trends of hemoglobin oximetry: Do they help predict blood transfusion during trauma patient resuscitation? Anesth. Analg. 2016, 122, 115-125. [CrossRef]

11. Murphy, S.M.; Omar, S. The clinical utility of noninvasive pulse co-oximetry hemoglobin measurements in dark-skinned critically ill patients. Anesth. Analg. 2018, 126, 1519-1526. [CrossRef] [PubMed]

12. Bubenek-Turconi, S.I.; Văleanu, L.; Popescu, M.; Panaitescu, E.; Tomescu, D.; Cacoveanu, M.C.; Perel, A. Continuous noninvasive hemoglobin monitoring reflects the development of acute hemodilution after consecutive fluid challenges. Anesth. Analg. 2020, 130, 696-703. [CrossRef] [PubMed]

13. Munoz, X.; Torres, F.; Sampol, G.; Rios, J.; Marti, S.; Escrich, E. Accuracy and reliability of pulse oximetry at different arterial carbon dioxide pressure levels. Eur. Respir. J. 2008, 32, 1053-1059. [CrossRef] [PubMed]

14. Lee, H.S.; Yoo, J.W.; Kim, H.Y.; Kim, N.Y.; Kim, J.E. Accuracy of continuous and noninvasive hemoglobin monitoring in the presence of CO2 insufflation: An observational pilot study. Med. Sci. Monit. 2021, 27, e933027. [CrossRef] [PubMed]

15. Macknet, M.R.; Allard, M.; Applegate, R.L., 2nd; Rook, J. The accuracy of noninvasive and continuous total hemoglobin measurement by pulse CO-Oximetry in human subjects undergoing hemodilution. Anesth. Analg. 2010, 111, 1424-1426. [CrossRef] [PubMed]

16. Chan, E.D.; Chan, M.M.; Chan, M.M. Pulse oximetry: Understanding its basic principles facilitates appreciation of its limitations. Respir. Med. 2013, 107, 789-799. [CrossRef]

17. Nitzan, M.; Romem, A.; Koppel, R. Pulse oximetry: Fundamentals and technology update. Med. Devices 2014, 7, 231-239. [CrossRef]

18. Miller, R.D.; Ward, T.A.; Shiboski, S.C.; Cohen, N.H. A Comparison of three methods of hemoglobin monitoring in patients undergoing spine surgery. Anesth. Analg. 2011, 112, 858-863. [CrossRef]

19. Shabaninejad, H.; Ghadimi, N.; Sayehmiri, K.; Hosseinifard, H.; Azarfarin, R.; Gorji, H.A. Comparison of invasive and noninvasive blood hemoglobin measurement in the operating room: A systematic review and meta-analysis. J. Anesth. 2019, 33, 441-453. [CrossRef]

20. Isosu, T.; Obara, S.; Hosono, A.; Ohashi, S.; Nakano, Y.; Imaizumi, T.; Mogami, M.; Murakawa, M. Validation of continuous and noninvasive hemoglobin monitoring by pulse CO-oximetry in Japanese surgical patients. J. Clin. Monit. Comput. 2013, 27, 55-60. [CrossRef]

21. Kim, S.H.; Lilot, M.; Murphy, L.S.; Sidhu, K.S.; Yu, Z.; Rinehart, J.; Cannesson, M. Accuracy of continuous noninvasive hemoglobin monitoring: A systematic review and meta-analysis. Anesth. Analg. 2014, 119, 332-346. [CrossRef] [PubMed]

22. Nguyen, B.V.; Vincent, J.L.; Nowak, E.; Coat, M.; Paleiron, N.; Gouny, P.; Ould-Ahmed, M.; Guillouet, M.; Arvieux, C.C.; Gueret, G. The accuracy of noninvasive hemoglobin measurement by multiwavelength pulse oximetry after cardiac surgery. Anesth. Analg. 2011, 113, 1052-1057. [CrossRef] [PubMed] 
23. Barker, S.J.; Shander, A.; Ramsay, M.A. Continuous noninvasive hemoglobin monitoring: A measured response to a critical review. Anesth. Analg. 2016, 122, 565-572. [CrossRef] [PubMed]

24. James, W.; Iain, C. Respiration: Gas transfer. Anaesth. Intensive Care Med. 2005, 6, 363-366.

25. Kuznetsova, D.V.; Kulikov, V.P. Cerebrovascular and systemic hemodynamic response to carbon dioxide in humans. Blood Press. Monit. 2014, 19, 81-89. [CrossRef]

26. Walløe, L. Arterio-venous anastomoses in the human skin and their role in temperature control. Temperature 2016, 3, 92-103. [CrossRef]

27. Cicha, I.; Suzuki, Y.; Tateishi, N.; Maeda, N. Changes of RBC aggregation in oxygenation-deoxygenation: $\mathrm{pH}$ dependency and cell morphology. Am. J. Physiol. Heart Circ. Physiol. 2003, 284, H2335-H2342. [CrossRef]

28. Berkow, L. Factors affecting hemoglobin measurement. J. Clin. Monit. Comput. 2013, 27, 499-508. [CrossRef]

29. Basaranoglu, G.; Bakan, M.; Umutoglu, T.; Zengin, S.U.; Idin, K.; Salihoglu, Z. Comparison of $\mathrm{SpO}_{2}$ values from different fingers of the hands. Springerplus 2015, 4, 561. [CrossRef] 